\title{
Comparison of sulfamethoxazole adsorption by activated carbon and biochar in seawater
}

\author{
Wei Meng ${ }^{1,2}$, Mengying Shao ${ }^{1,2}$, Mei Shi ${ }^{1,2, *}$ \\ ${ }^{1}$ Institute of Coastal Environmental Pollution Control, Key Laboratory of Marine Environment and Ecology, Ministry of Education \\ Ocean University of China, 266100 Qingdao, China \\ ${ }^{2}$ College of environmental science and engineering, Ocean University of China, 266100 Qingdao, China
}

\begin{abstract}
Antibiotics, a type of emerging contaminants in marine environment, have posed serious threats to human health and ecological function. Biochar has been widely used in the remediation of multiple pollutants due to low cost and good adsorption characteristics. However, the adsorption characteristics of biochar for antibiotics in seawater are still unclear. Therefore, a coconut shell activated carbon (AC) and a sludge biochar produced at $700{ }^{\circ} \mathrm{C}$ (SB700) were selected to carry out batch adsorption experiments of sulfamethoxazole (SMX) under different adsorbent dosage and different initial concentration of SMX. These results showed that the maximum removal rate $(R)$ of AC and SB700 was $99.9 \%$ and $97.9 \%$, the maximum adsorption capacity $\left(Q_{\mathrm{e}}\right)$ was $13.7 \mathrm{mg} \mathrm{g}^{-1}$ and $1.6 \mathrm{mg} \mathrm{g}^{-1}$, and the maximum adsorption coefficient $\left(K_{d}\right)$ was $2142 \mathrm{~L} \mathrm{~g} \mathrm{~g}^{-1}$ and $5.1 \mathrm{~L} \mathrm{~g}^{-1}$, respectively. Compared with SB700, AC showed the excellent performance in SMX adsorption. This study provided theoretical support and experimental basis for the development of highly efficient antibiotic adsorbents in marine ecosystem.
\end{abstract}

\section{Introduction}

Since the widespread production of antibiotics in 1940s, the irrational and abuse of antibiotics has brought about the amazing growth of antimicrobial resistance (AMR) in the world to a great extent [1]. Antibiotics are widely used in mariculture because they can prevent and control bacterial diseases. However, the illegal use of antibiotics not only changes the biological community structure in the marine environment, but also destroys the healthy operation of the marine ecosystem and restricts the development of marine economy [2]. The accumulation of antibiotics leads to the production of antibiotic resistance genes (ARGs) in seawater [3]. Sulfonamides are widely used in the mariculture as a result of its inexpensive cost and high bactericidal efficiency [4]. Sulfonamides have been found in 13 main mariculture farms in China, with concentrations ranging from 62.0 $374 \mathrm{ng} \mathrm{L}^{-1}$ [5]. Among them, sulfamethoxazole (SMX) is a typical veterinary antibiotic, which can accumulate for a long time and contribute to the horizontal gene transfer of ARGs [6]. Therefore, it is of increasing significance to control the impact of antibiotic pollution in the marine environment on the planetary health of all living things.

The methods to remove antibiotics include oxidation, photodegradation, biodegradation and adsorption [7]. As a common technology to remove antibiotics, adsorption has attracted more and more attention due to its advantages of simple operation and good treatment effect. Biochar is an ideal adsorbent which has the characteristics of large specific surface area, high porosity and rich functional groups [8,9]. Activated carbon is also a widely studied adsorption material. Compared with activated carbon, biochar may be more promising in market application because of its low cost $[10,11]$. However, there are few studies on the adsorption of antibiotics in seawater by biochar, and the adsorption characteristics are not clear.

The specific purposes of this research were to compare the adsorption characteristics of SMX on biochar and activated carbon. This study will provide a theoretical support for constructing a marine antibiotic pollution remediation technology using the carbonaceous materials.

\section{Materials and Methods}

\subsection{Chemicals}

SMX, a model sulfanilamide, was bought from SigmaAldrich Co. Coconut shell activated carbon (AC) was purchased from Pingdingshan Greenwood Activated Carbon Co. Sludge biochar (SB700) was purchased from the UK Biochar Research Center at Edinburgh University. AC and SB700 were crushed through 200 mesh sieve and dried overnight at $60{ }^{\circ} \mathrm{C}$ for following analysis.

\footnotetext{
*Corresponding author: shimei@stu.ouc.edu.cn
} 


\subsection{Adsorption experiment}

At different initial concentrations of SMX, the adsorption experiments under AC and SB700 were carried out in glass bottles. The background solution of $\operatorname{SMX}\left(100 \mathrm{mg} \mathrm{L}^{-1}\right)$ was natural seawater $(\mathrm{pH}=8.0 \pm 0.02)$ filtered through a $0.22 \mu \mathrm{m}$ membrane. The experimental conditions of batch adsorption were: the initial concentration of SMX were $0.5,5$ and $50 \mathrm{mg} \mathrm{L}^{-1}$, the addition of AC and SB700 were 25, 50 and $100 \mathrm{mg}$, and the volume of diluted SMX solution was $7 \mathrm{~mL}$. All treatment groups were incubated at $150 \mathrm{rpm}$ and $25^{\circ} \mathrm{C}$ for $48 \mathrm{~h}$ and avoided light, and the $\mathrm{pH}$ value of adsorption equilibrium is 8.0. After adsorption, the supernatant was collected and the concentration of antibiotics was measured by HPLC (1260, Agilent, USA) fitted with a C18 column $(250 \times 4.60 \mathrm{~mm}$, Agilent, USA $)$ under wavelength of $265 \mathrm{~nm}$. The mobile phase was a mixture of $0.05 \mathrm{M}$ phosphoric acid and acetonitrile with a ratio of $75: 25(\mathrm{v} / \mathrm{v})$, the velocity of flow of mobile phase was $1.0 \mathrm{~mL} \mathrm{~min}^{-1}[12]$.

\subsection{Data analysis}

The removal rate $(R)$ of SMX is calculated according to equation (1).

$$
R=\left(C_{0}-C_{\mathrm{e}}\right) / C_{0}
$$

where the initial concentration of SMX and the concentration of SMX after adsorption were expressed in $C_{0}$ and $C_{\mathrm{e}}\left(\mathrm{mg} \mathrm{L}^{-1}\right)$, respectively.

The adsorption capacity $\left(Q_{e}\right)$ and adsorption coefficient $\left(K_{d}\right)$ are calculated according to equation (2) and equation (3), respectively.

$$
\begin{aligned}
Q_{\mathrm{e}} & =\left(C_{0}-C_{\mathrm{e}}\right) \cdot V / m \\
K_{\mathrm{d}} & =Q_{\mathrm{e}} / C_{\mathrm{e}}
\end{aligned}
$$

where the volume of SMX solution was expressed in $V$ $(\mathrm{mL})$; and the mass of AC and SB700 was expressed in $m$ (mg).

All experimental data were expressed as mean \pm standard deviation $(\mathrm{n} \geq 3)$. Statistical Product and Service Solutions Software (SPSS 20.0) was used to analyze the significant differences. One-way analysis of variance (ANOVA) were used to analyze the significant differences among different treatments.

\section{Results and discussion}

\subsection{Removal rate of SMX}

The effect of activated carbon and biochar on the $R$ of SMX were shown in Fig.1. In the three groups of experiments with all the initial concentration of SMX $\left(0.5,5,50 \mathrm{mg} \mathrm{L}^{-1}\right)$, the $R$ of SMX by AC was $98.1-$ $99.9 \%$, almost completely removing SMX. The reason for the high removal rate of SMX by AC because of huge specific surface area and numerous micropore. In the adsorption process, AC has not reached saturation and can continue to be adsorbed. When the initial concentration of SMX was constant, the $R$ of SMX by SB700 increased with increasing addition of SB700. With the addition of SB700 from $5 \mathrm{mg}$ to $100 \mathrm{mg}$, the $R$ increased from $11.7-81.2 \%$ to $34.7-97.9 \%$. The reason is that the increasing biochar addition provided more adsorption sites for SMX, so the total adsorption capacity and removal rate increased accordingly. However, the removal rate of SMX by SB700 decreased as the increasing initial concentration of SMX. When the initial concentration of SMX increased from $0.5 \mathrm{mg} \mathrm{L}^{-1}$ to $50 \mathrm{mg} \mathrm{L}^{-1}$, the $R$ decreased from $81.2-97.9 \%$ to $11.7-$ $34.7 \%$. The reason for this phenomenon may be that SB700 have reached saturation in the adsorption process.
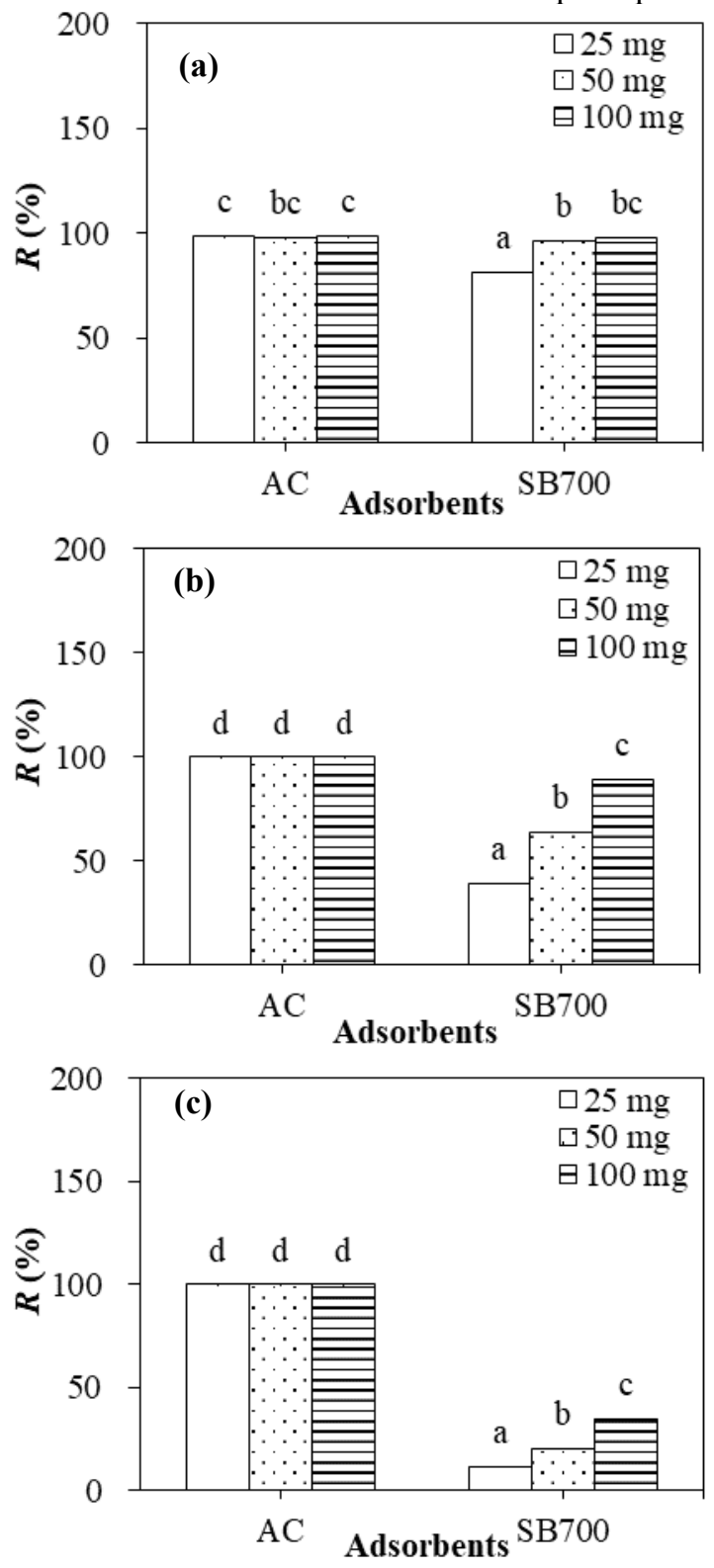

Fig. 1. Removal rate of SMX by AC and SB700 with different addition. Initial concentrations of SMX: (a) $0.5 \mathrm{mg} \mathrm{L}^{-1}$, (b) 5 $\mathrm{mg} \mathrm{L}^{-1}$, (c) $50 \mathrm{mg} \mathrm{L}^{-1}$. AC: coconut shell activated carbon. SB700: Biochar derived from sludge pyrolysis at $700{ }^{\circ} \mathrm{C}$. Adsorption conditions: AC and SB700 $(25 \mathrm{mg}, 50 \mathrm{mg}$ and 100 $\mathrm{mg}$ ) were added to $7 \mathrm{~mL} \mathrm{SMX} \mathrm{solution} \mathrm{and} \mathrm{adsorbed} \mathrm{at} 25^{\circ} \mathrm{C}$ for $48 \mathrm{~h}$, the $\mathrm{pH}$ value of adsorption equilibrium was 8.0. 


\subsection{Adsorption capacity of SMX}

The effect of activated carbon and biochar on the unit $Q_{e}$ were shown in Fig.2. The maximum unit $Q_{e}$ of $\mathrm{AC}$ and $\mathrm{BC}$ were $13.7 \mathrm{mg} \mathrm{g}^{-1}$ and $1.6 \mathrm{mg} \mathrm{g}^{-1}$, respectively. The unit $Q_{e}$ of AC and SB700 for SMX showed the same trend. At the same initial concentration of SMX, the unit $Q_{e}$ of AC and SB700 decreased with increasing AC and SB700. The unit $Q_{e}$ of AC and SB700 decreased by $74.8-75.0 \%$ and $27.5-64.0 \%$ respectively with the increase of carbon content from $25 \mathrm{mg}$ to $100 \mathrm{mg}$. The reason may be that the active adsorption sites on the surface of AC and SB700 are more likely to contact with SMX molecules when the addition of AC and SB700 are low. Aggregation may occur between highly added carbonaceous materials, and the active adsorption sites on the carbonaceous materials decrease, resulting in a decrease in the unit adsorption. However, when the initial concentration of SMX was constant, the unit $Q_{e}$ increased with the increasing initial concentration of SMX. However, as the initial concentration of SMX increased from $0.5 \mathrm{mg} \mathrm{L}^{-1}$ to $50 \mathrm{mg} \mathrm{L}^{-1}$, the unit $Q_{e}$ of AC and SB700 increased by $9871-9938 \%$ and 1344 $3388 \%$. The increase in the unit $Q_{e}$ is a result of the concentration gradient and the larger adsorption driving force between high concentrations of SMX and carbonaceous materials, and SMX molecules more easily diffuse into the pores in the carbonaceous materials.
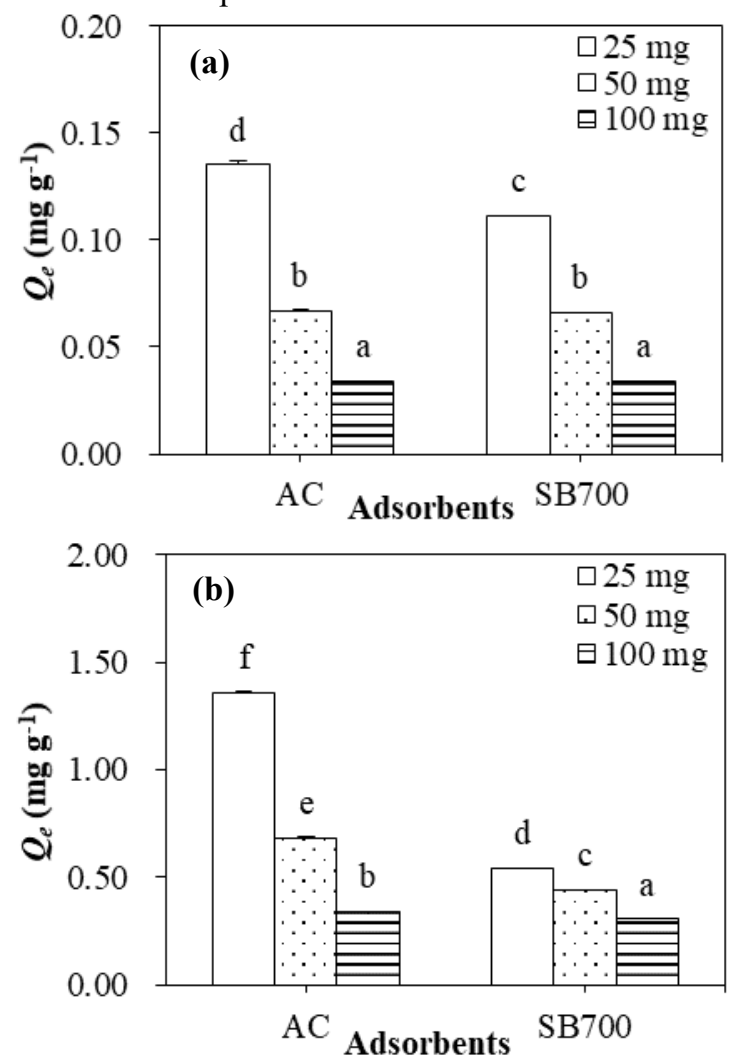

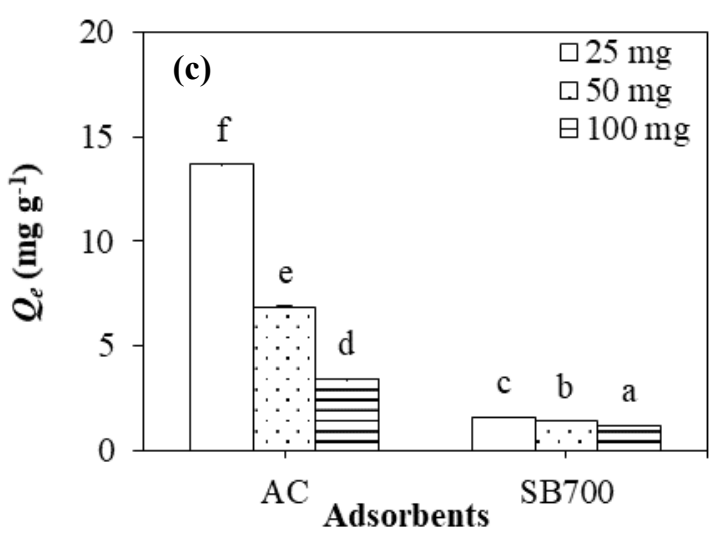

Fig. 2. Adsorption capacities of SMX by AC and SB700 with different addition. Initial concentrations of SMX: (a) $0.5 \mathrm{mg} \mathrm{L}^{-}$

${ }^{1}$, (b) $5 \mathrm{mg} \mathrm{L}^{-1}$, (c) $50 \mathrm{mg} \mathrm{L}^{-1}$. AC: coconut shell activated carbon. SB700: Biochar derived from sludge pyrolysis at $700{ }^{\circ} \mathrm{C}$. Adsorption conditions: AC and SB700 $(25 \mathrm{mg}, 50 \mathrm{mg}$ and $100 \mathrm{mg}$ ) were added to $7 \mathrm{~mL}$ SMX solution and adsorbed at $25^{\circ} \mathrm{C}$ for $48 \mathrm{~h}$, the $\mathrm{pH}$ value of adsorption equilibrium was 8.0 .

\subsection{Adsorption coefficient of SMX}

The effect of activated carbon and biochar on the $K_{\mathrm{d}}$ were shown in Fig.3. The maximum $K_{\mathrm{d}}$ values of $\mathrm{AC}$ and $\mathrm{BC}$ were $2142 \mathrm{~L} \mathrm{~g}^{-1}$ and $5.1 \mathrm{~L} \mathrm{~g}^{-1}$. When the initial concentration of SMX was $5 \mathrm{mg} \mathrm{L}^{-1}$ and $50 \mathrm{mg} \mathrm{L}^{-1}$, the $K_{\mathrm{d}}$ of AC decreased by $74.8-76.5 \%$ with the increase of AC dosage from $25 \mathrm{mg}$ to $100 \mathrm{mg}$. This is consistent with the previous conclusion that $Q_{e}$ and $K_{\mathrm{d}}$ decrease with the increase of $\mathrm{AC}$ addition. The increasing concentration of SB700 had no significant effect on $K_{\mathrm{d}}$. As the initial concentration of SMX increased from 0.5 $\mathrm{mg} \mathrm{L}^{-1}$ to $50 \mathrm{mg} \mathrm{L}^{-1}, K_{\mathrm{d}}$ of AC increased by $720-3814 \%$. As mentioned above, AC did not reach the adsorption saturation and there were a large number of active adsorption sites on AC, SMX could still be adsorbed completely after increasing SMX concentration, so the $K_{\mathrm{d}}$ of AC increased with the increase of initial concentration, and $K_{\mathrm{d}}$ was significantly higher than SB700. However, the $K_{\mathrm{d}}$ of SB700 decreased by 97.0 $99.3 \%$. This is also consistent with the previous conclusion that the adsorption sites of SB700 gradually saturate with the increase of SMX concentration. 

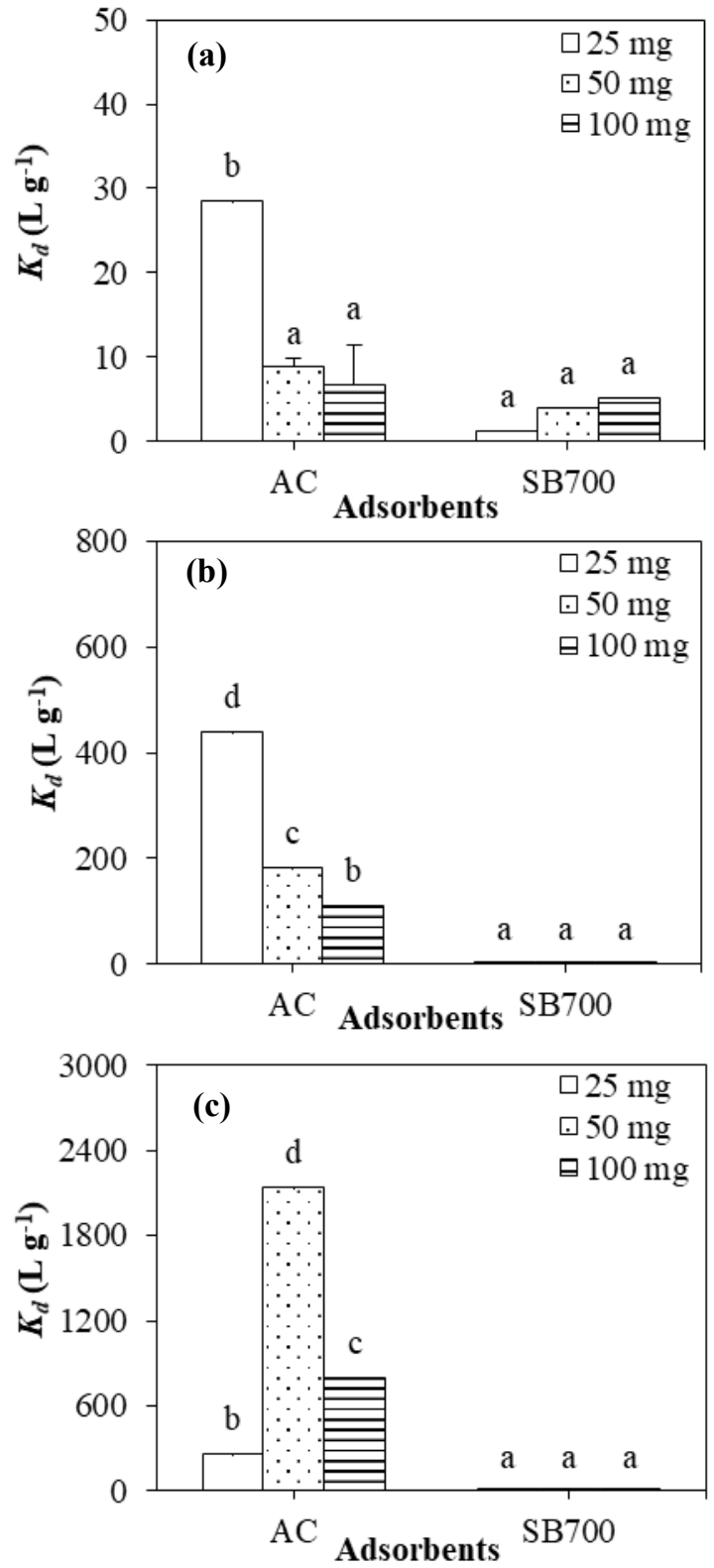

Fig. 3. Adsorption coefficients of SMX by AC and SB700 with different addition. Initial concentrations of SMX: (a) $0.5 \mathrm{mg} \mathrm{L}$

${ }^{1}$, (b) $5 \mathrm{mg} \mathrm{L}^{-1}$, (c) $50 \mathrm{mg} \mathrm{L}^{-1}$. AC: coconut shell activated carbon. SB700: Biochar derived from sludge pyrolysis at $700{ }^{\circ} \mathrm{C}$. Adsorption conditions: AC and SB700 $(25 \mathrm{mg}, 50 \mathrm{mg}$ and $100 \mathrm{mg}$ ) were added to $7 \mathrm{~mL}$ SMX solution and adsorbed at $25{ }^{\circ} \mathrm{C}$ for $48 \mathrm{~h}$, the $\mathrm{pH}$ value of adsorption equilibrium was 8.0.

\subsection{Potential adsorption mechanisms}

Compared with SB700, AC showed the excellent performance in SMX adsorption. The main mechanisms of SMX adsorption by carbonaceous materials are pore filling, $\pi-\pi$ EDA interaction, hydrogen bonding and hydrophobic interaction [13]. The excellent adsorption characteristics of $\mathrm{AC}$ is mainly attributed to its huge specific surface area and numerous pore structure, and the main adsorption mechanism is pore filling. Previous studies have demonstrated that microporous and mesoporous structures can significantly enhance the adsorption capacity of AC for SMX [14]. SB700 contains a lot of aromatic structures and is more prone to $\pi-\pi$ EDA interaction [15].

\section{Conclusions}

This study demonstrated that the adsorption capacity of $\mathrm{AC}$ was higher than that of SB700. The main adsorption mechanisms of AC and SB700 were pore filling and $\pi-\pi$ EDA interaction, respectively. Because of its low price and high removal rate of SMX, biochar can be used as a substitute for activated carbon, which has a great market prospect in practical application. Therefore, this study provided experimental support and theoretical basis for the development of environmental and economic remediation technology of antibiotic pollution in the seawater.

\section{Acknowledgment}

This study was supported by Shandong Province Natural Science Foundation (ZR2019MD017).

\section{References}

1. R. Hao, R. Zhao, S. Qiu, L. Wang, H. Song, Science 348, 1100-1101(2015)

2. Q. Han, X. Zhao, X. Zhang, C. Wang, S. Song, G. Wang, Environ Int 138 (2020)

3. M. Qiao, G. Ying, A. C. Singerd, Y. Zhu, Environ Int 110, 160-172 (2017)

4. J. Tolls, Environ Sci Technol 35, 3397 (2001)

5. C. Chen, L. Zheng, J. Zhou, H. Zhao, Sci Total Environ 580, 1175-1184 (2017)

6. J. Jutkina, N. P. Marathe, C. F. Flach, D. G. J. Larsson, Sci Total Environ 616-617, 172-178 (2018)

7. A. S. Oberoi, Y. Jia, H. Zhang, S. K. Khanal, H. Lu, Environ Sci Technol 53, 7234-7264 (2019)

8. X. Xiao, B. Chen; Z. Chen, L. Zhu, J. L. Schnoor, Environ Sci Technol 52, 5027-5047 (2018)

9. H. Zheng, Q. Zhang, G. Liu, X. Luo, F. Li, Y. Zhang, Z. Wang, Sci Total Environ 657, 953-962 (2019)

10. H. A. Alhashimi, C. B. Aktas, Resour Conserv Recy 118, 13-26 (2017)

11. M. Ahmad, A. U. Rajapaksha, J. E. Lim, M. Zhang, N. Bolan, D. Mohan, M. Vithanage, S. S. Lee, Y. S. Ok, Chemosphere 99, 19-33 (2014)

12. H. Zheng, Z. Wang, J. Zhao, S. Herbert, B. Xing, Environ Pollut 181, 60-67 (2013)

13. G.Prasannamedha, P. S. Kumar, J Clean Prod 250, 119553 (2020)

14. L. Nielsen, M. J. Biggs, W. Skinner, T. J. Bandosz, Carbon 80, 419-432 (2014)

15. F. Reguyal, A. K. Sarmah, Sci Total Environ 628629, 722-730 (2018) 